\title{
Performance and microbial community of carbon nanotube fixed-bed microbial fuel cell continuously fed with hydrothermal liquefied cornstalk biomass
}

\author{
Zhidan Liu ${ }^{\mathrm{a}, *}$, Yanhong $\mathrm{He}^{\mathrm{a}}$, Ruixia Shen ${ }^{\mathrm{a}}$, Zhangbing Zhu ${ }^{\mathrm{a}}$, Xin-Hui Xing ${ }^{\mathrm{b}}$, \\ Baoming Li ${ }^{\text {a }}$, Yuanhui Zhang ${ }^{\mathrm{a}, \mathrm{c}}$
}

${ }^{a}$ Laboratory of Environment-Enhancing Energy (E2E), and Key Laboratory of Agricultural

Engineering in Structure and Environment, Ministry of Agriculture, College of Water

Resources and Civil Engineering, China Agricultural University, Beijing, 100083, China;

${ }^{b}$ Department of Chemical Engineering, Tsinghua University, Beijing 100084, China;

${ }^{c}$ Department of Agricultural and Biological Engineering, University of Illinois at Urbana-Champaign, Urbana, IL 61801, U.S.A.

${ }^{*}$ Corresponding author.

Fax:+86-10-62737329; Tel.: +86-10-62737329.

E-mail address: zdliu@cau.edu.cn (Z. Liu)

Laboratory of Environment-Enhancing Energy (E2E), China Agricultural University, Beijing, 100083, China 
Abstract: Hydrothermal liquefaction (HTL) is a green technology for biomass pretreatment with the omission of hazardous chemicals. This study reports a novel integration of HTL and carbon nanotubes (CNTs) fixed-bed microbial fuel cell (FBMFC) for continuous electricity generation from cornstalk biomass. Two FBMFCs in parallel achieved similar performance fed with cornstalk hydrolysate at different organic loading rates (OLRs) $(0.82-8.16 \mathrm{~g} / \mathrm{L} / \mathrm{d})$. About $80 \%$ of Chemical oxygen demand (COD) and Total organic carbon (TOC) was removed from low-Biochemical oxygen demand (BOD)/COD (0.16) cornstalk hydrolysate at 8.16 $\mathrm{g} / \mathrm{L} / \mathrm{d}$, whereas a maximum power density $\left(680 \mathrm{~mW} / \mathrm{m}^{3}\right)$ was obtained at $2.41 \mathrm{~g} / \mathrm{L} / \mathrm{d}$, and a smallest internal resistance $\left(\mathrm{R}_{\text {in }}\right)(28 \Omega)$ at $3.01 \mathrm{~g} / \mathrm{L} / \mathrm{d}$. Illumina MiSeq sequencing reveals the diverse microbial structure induced by the complex composition of cornstalk hydrolysate. Distinguished from Proteobacteria, which a number of exoelectrogens belong to, the identified dominant genus Rhizobium in FBMFC was closely related to degradation of cellulosic biomass.

Keywords: Cornstalk, Hydrothermal liquefaction, Microbial fuel cell, Microbial community 


\section{Introduction}

Lignocellulose biomass, such as cornstalk, is one of the major renewable biomass resources. Hemicellulose and cellulose are two main components of lignocellulosic biomass and feedstock for downstream fermentation. However, it has a natural recalcitrance to degradation and utilization (Himmel, 2008). Hydrothermal liquefaction (HTL) is a thermochemical process where biomass is liquefied in a closed oxygen-free reactor at a certain temperature $\left(100 \sim 500^{\circ} \mathrm{C}\right)$ and pressure $(5 \sim 30$ MPa) using water as the solvent (Tian et al., 2014). In comparison to other pretreatment approaches, HTL has its specific characteristics, including the omission of hazardous chemicals and no need for solvents recycling (Nitsos et al., 2013). The challenge of HTL pretreatment is the difficulty in concise control of thermochemical reactions, which otherwise causes the formation of complex hydrolysate (Möller et al., 2011). The hydrolysate is composed of not only sugars, but also volatile fatty acids (VFAs), aldehydes, and phenols, which might inhibit the downstream fermentation (Möller et al., 2011).

Microbial fuel cell (MFC) allows a direct energy conversion into electricity from organic matter and has exhibited several potential applications in the fields of environment and energy (Logan and Rabaey, 2012). Different from ethanol fermentation, electricity generation through MFC has a broader feedstock spectrum (Pant et al., 2010), such as sugars, VFAs and even furan derivatives (Luo et al., 2010). Specifically, great efforts have been made to develop MFC based technology to deal with cellulosic biomass (Ahmad et al., 2013). However, exoelectrogens in cellulosic MFC alone may suffer from substrate accessibility and hydrolysis limitations (Ahmad et al., 2013).

There are currently two main approaches for electricity generation through cellulosic MFC. The first is based on completely biological conversion, for instance consolidated bioprocessing of cellulosic biomass (Lynd et al., 2005). This process 
could be catalyzed by artificially constructing a multi-functional microbial consortia (Ren et al., 2007), or employing an enriched microbial community alone (Rismani-Yazdi et al., 2007) or mixed with the cellulase (Rezaei et al., 2008). For instance, microbial consortia (Ren et al., 2007) were designed consisting of a cellulose-degrading bacteria Clostridium cellulolyticum and an exoelectrogen Geobacter sulfurreducens. Prominent synthetic effect of these two strains was observed in the designed MFC. By adding cellulase to a pre-acclimated MFC consisting of exoelectrogen, the cellulose was also rapidly converted to sugars and produce power in an MFC (Rezaei et al., 2008). Besides cellulose, power was also produced from more complex lignocellulosic biomass, such as rice straw (Hassan et al., 2014) and cornstalk (Wang et al., 2009). A key issue of these combined microbial consortia is how to make the consortia genetically stable (Elkins et al., 2010) and maintain the long-term efficient operation of MFC. Recently, solid lignocellulosic biomass, such as corncobs (Gregoire and Becker, 2012) and cow manure (Wang et al., 2014) with a total solid (TS) over $15 \%$, was directly used as feedstocks by combining the concept of leach-bed composing with MFC using natural mixed culture as inoculums. However, mass transfer resistance may be a great challenge for such MFC operation. The second approach is the combination of physic-chemical pretreatment with MFC. Steam-explosion was frequently used for the treatment of biomass (Liu et al., 2015). It was firstly introduced to treat cornstalk, which was used as the feedstock in a batch MFC study (Zuo et al., 2006). Wheat straw was pretreated with HTL and the hydrolysate was used for electricity generation in a batch two-chamber MFC. However, fermentation inhibitors, such as furan derivatives and phenols ( $\mathrm{Li}$ and Chen, 2008; Wang et al., 2013) were released during pretreatment. Furan derivatives, including furfural (FUR) and 5-hydroxymethyl furfural (HMF), are notorious fermentation inhibitors through reducing cell growth rate and lowering cell membrane permeability (Wang et al., 2013). Therefore, the biggest challenge of MFC fed with biomass hydrolysate is to enrich robust exoelectrogens suitable to deal with the 
feedstock in a complex composition, including sugars, organic acids, furan derivatives, phenols and other components. Besides these, most reported cellulosic MFCs (Zuo et al., 2006; Wang et al., 2014; Zhang et al., 2009) were operated in batch mode, depressing the application potential of such technology.

The purposes of this study were to 1) investigate the feasibility of continuous conversion and power generation from HTL treated cornstalk biomass through carbon nanotubes (CNTs) based FBMFC under different organic loading rates (OLRs); 2) study microbial structure and evolution of exoelectrogen using next generation sequencing on the Illumina MiSeq platform.

\section{Materials and methods}

\subsection{Cornstalk and HTL treatment}

Cornstalk was collected from Golden-sun farm (Beijing, China). It was dried, milled and screened through 10-40 mesh sieves. As shown in Table 1, the dry biomass mainly consisted of cellulose (45.06\%), hemicellulose (29.68\%), and lignin (5.65\%). HTL of cornstalk was performed in a $1.8 \mathrm{~L}$ batch reactor (Model 4578, Parr Instrument Company, USA), similar to the procedure described previously (Li et al., 2014). The cornstalk was mixed with water to achieve a TS of $20 \%$ and then put into the reactor. After the reactor was sealed, pure nitrogen gas was flowed to exclude oxygen and reach a set initial pressure as $2.5 \mathrm{MPa}$ for the experiments. The retention time started when the reactor reached the set temperature $\left(312^{\circ} \mathrm{C}\right)$, and was set as 0 min with a mixing speed of $400 \mathrm{rpm}$. All cellulose and hemicellulose were liquefied through HTL and the solid residue contained $22.08 \%$ of lignin (Table 1). The liquefaction yield of cornstalk was 59\%. The cornstalk hydrolysate contained 64.59 $\mathrm{g} / \mathrm{L}$ total VFAs (TVFAs), $5.4 \mathrm{~g} / \mathrm{L}$ reducing sugars, $0.67 \mathrm{~g} / \mathrm{L} \mathrm{HMF}$ and $0.74 \mathrm{~g} / \mathrm{L}$ FUR with a $\mathrm{pH}$ of 3.34. In addition, the analysis of Gas Chromatograph-Mass Spectrometer 
(GC-MS) revealed the complexity of cornstalk hydrolysate, and many other organic chemicals were included, such as phenols, ketones and esters (Fig.S1). Chemical oxygen demand (COD), Total organic carbon (TOC), Biochemical oxygen demand (BOD) and IC (Inorganic carbon) of hydrolysate were $44.94 \mathrm{~g} / \mathrm{L}, 18.51 \mathrm{~g} / \mathrm{L}, 7.37 \mathrm{~g} / \mathrm{L}$ and $0.06 \mathrm{~g} / \mathrm{L}$, respectively. Most measurements were performed in triplicates, and the mean values were presented. The cornstalk hydrolysate had a BOD/COD of 0.16 , indicating its characteristics of poor biodegradability. The detailed analysis method was described in Section 2.4.

\subsection{Inoculum and electrolyte}

The inoculum was collected from an anaerobic digester of Xiaohongmen Municipal Wastewater Treatment Plant (Beijing, China). Cornstalk hydrolysate was diluted for the desired experiment, amended with trace elements $(10 \mathrm{~mL} / \mathrm{L})$ and minerals solutions $(10 \mathrm{~mL} / \mathrm{L})$ and adjusted to $\mathrm{pH} 7.0$ prior to use. The catholyte consisted of a $50 \mathrm{mM}$ phosphate buffer $\left(0.31 \mathrm{~g} \mathrm{NH} \mathrm{N}_{4} \mathrm{Cl} / \mathrm{L}, 0.13 \mathrm{~g} \mathrm{KCl} / \mathrm{L}, 2.45 \mathrm{~g} \mathrm{NaH}_{2} \mathrm{PO}_{4} \cdot \mathrm{H}_{2} \mathrm{O} / \mathrm{L}\right.$, $\left.4.58 \mathrm{~g} \mathrm{Na}_{2} \mathrm{HPO}_{4} / \mathrm{L}, \mathrm{pH} 6.8-7.1\right)$.

\subsection{MFC structure and experimental procedure}

FBMFC consisted of two chambers as previously described (He et al., 2015). The anode chamber had a working volume of $290 \mathrm{ml}$ and was packed with multi-walled CNTs (Cnano Technology Company, Beijing, China) with a packing density of 0.13

$\mathrm{g} / \mathrm{cm}^{3}$. Carbon fiber felt with a projected area of $515 \mathrm{~cm}^{2}$ was placed around the CNTs as the current collector. The CNTs and carbon fiber felt was soaked with acetone, washed with deionized water, and heat treated at $450^{\circ} \mathrm{C}$ for $30 \mathrm{~min}$ prior to use. In addition, the anode chamber was connected with a $\mathrm{KCl}$ solution containing sterile $\mathrm{Ag} / \mathrm{AgCl}$ reference electrodes through a salt bridge for desirable experiments. The 
cathode was made of a carbon fiber felt with a projected area of $42 \mathrm{~cm}^{2}$. The two chambers were separated by a proton exchange membrane (DuPont Nafion-117), which was supported by two pieces of plastics. The membrane was treated with $5 \%$ (v/v) sulfuric acid at $80{ }^{\circ} \mathrm{C}$ for $2 \mathrm{~h}$, and then was cleaned with deionized water prior to use.

The FBMFC system consisted of upflow FBMFC, gas-liquid separation and collection, feedstock delivery and data acquisition unit. Two identical FBMFCs were operated in parallel to study microbial stability of bioelectricity generation from cornstalk hydrolysates. Dissolved oxygen was removed from the anodic medium by purging with nitrogen gas for 15 min before use. In order to enrich exoelectrogens, the FBMFC was first continuously run for almost half a year fed with sugar-rich synthetic wastewater at room temperature $\left(25 \pm 2^{\circ} \mathrm{C}\right)(\mathrm{He}$ et al., 2015). The feedstock was then switched to cornstalk hydrolysate with a flow rate of $0.3 \mathrm{ml} / \mathrm{min}$. The effluent in the anode chamber was separated through the gas-liquid separator, whereas the effluent in the cathode chamber was recycled with an oxygen-saturated phosphate buffer. Cornstalk hydrolysate at OLRs of $0.82-8.16 \mathrm{~g} \mathrm{COD} / \mathrm{L} / \mathrm{d}$ was fed into the anode chamber of the FBMFC. Note that hydraulic retention time (HRT) of the MFC anode was kept constant as $16 \mathrm{~h}$ throughout the experiments. The analysis of electrochemical properties of MFC and metabolites was performed when the electricity generation reached the steady state after more than three HRTs at each OLR.

\subsection{Analytical methods}

\subsubsection{The analysis of cornstalk and liquid products}

Biochemical analysis of cornstalk and its solid residue after HTL was carried out based on dry biomass as previously described (Li et al., 2014). Ash content was 
measured by burning samples at $575^{\circ} \mathrm{C}$ for more than $4 \mathrm{~h}$. Contents of cellulose, hemicelluose and lignin were determined using a fiber analyzer (A220, ANKOM Technology Co., NY, USA).

COD of liquid products was measured using a rapid spectrophotometric method (HACH, USA). TOC and IC was analyzed using a Torch Combustion TOC analyzer (TOC-VCPN, Shimadzu Co., Tokyo, Japan). VFAs were analyzed by High Performance Liquid Chromatography (HPLC) (LC-10 AVP Shimadzu, Japan) using an ultraviolet detector and a synergi $4 \mathrm{u}$ Hydro-RP column. $5 \mathrm{mM} \mathrm{H}_{2} \mathrm{SO}_{4}$ was used as the mobile phase at a flow rate of $1 \mathrm{~mL} / \mathrm{min}$. When the electricity generation reached the steady state at each OLR, the COD and TOC of the influent and effluent, and the VFAs in the effluent were measured. Each sample was measured for three times, and the mean of the results was accepted. The samples were centrifuged at $25^{\circ} \mathrm{C}$ for 10 min and then filtered with a $0.45 \mu \mathrm{m}$ filter prior to test.

Organic chemicals in cornstalk hydrolysate $\left(\mathrm{V}_{\text {liquid phase }}: \mathrm{V}_{\text {diethyl ether }}=1: 9\right)$ were examined using a GC-MS (Model QP2010, Agilent DB-5 column). Helium was used as the carrier gas at a flow rate of $1.64 \mathrm{~mL} / \mathrm{min}$. The interface temperature and the injection temperature were both set at $250^{\circ} \mathrm{C}$, and the ion source temperature was set at $200^{\circ} \mathrm{C}$. The oven temperature was set at $35^{\circ} \mathrm{C}$ for $5 \mathrm{~min}$ followed by a temperature ramp of $25^{\circ} \mathrm{C} / \mathrm{min}$ to $130^{\circ} \mathrm{C}(4 \mathrm{~min}), 240^{\circ} \mathrm{C}(4 \mathrm{~min})$, and $280^{\circ} \mathrm{C}(7 \mathrm{~min})$. The mass spectrometer was operated at $70 \mathrm{eV}$. Scan range of mass spectrum was in $\mathrm{m} / \mathrm{z}$ of $35-500$.

\subsubsection{Electrochemical analysis}

The voltage between the anode and the cathode was automatically collected per min.

The power density, $P\left(W / m^{3}\right)$, was calculated using the formula $P=U^{2} /(R v)$, where $U$ (V) was the voltage of the external resistance $\left(\mathrm{R}_{\text {ext }}, 1000 \Omega\right)$, and $\mathrm{v}\left(\mathrm{m}^{3}\right)$ was the volume of the anode chamber. After a polarization experiment, an electrochemical workstation (CHI660E, Shanghai chenghua, China) was used for the analysis of electrochemical impedance spectroscopy (EIS). In order to measure the internal 
resistance $\left(\mathrm{R}_{\text {in }}\right)$ of the FBMFCs, EIS test was carried out at a frequency range of 0.01 $\mathrm{Hz}-100 \mathrm{kHz}$ and an alternating current signal of $0.01 \mathrm{~V}$ amplitude. EIS analysis was performed after the FBMFC circuit was disconnected for one hour. The MFC anode served as the working electrode, whereas the cathode was used as the counter and the reference electrode, in order to record the impedance spectra of FBMFC through the electrochemical station. The Nyquist plots were obtained after EIS test and $\mathrm{R}_{\text {in }}$ was calculated based on the sum of the resistances due to the ohmic polarization, activation polarization, and concentration polarization of MFCs (Oliveira et al., 2013). Each test was repeated three times.

\subsubsection{The analysis of microbial morphology and structure}

Microbial morphology was observed using scanning electron microscope (SEM, FEI Quanta 200). The microbial samples from FBMFC were fixed with $2.5 \%(\mathrm{v} / \mathrm{v})$ glutaraldehyde in $0.1 \mathrm{M}$ cacodylate, $\mathrm{pH} 7.2$ at $4^{\circ} \mathrm{C}$, washed with phosphate buffer $(0.1$ $\mathrm{M}, \mathrm{pH}$ 7.2) for three times (10 min/time) and then dehydrated stepwise using a gradient series of ethanol solutions $(50 \%, 70 \%, 80 \%, 90 \%, 100 \%, \mathrm{v} / \mathrm{v})$. The ethanol was then replaced with tertiary butanol and dried at $20{ }^{\circ} \mathrm{C}$ for $20 \mathrm{~min}$. Samples were finally coated with Au and observed using SEM.

The microbial diversity of inoculum and enriched microbial consortia through FBMFC was analyzed via Illumina MiSeq sequencing (Kumaraswamy et al., 2014). Genomic DNA was first extracted from samples using the E.Z.N.A DNA Isolation Kit (Omega Biotec, USA). The V4-V5 regions of the bacteria 16S ribosomal RNA gene were then amplified by GeneAmp PCR System (ABI company, USA) using primers 515F (5'-barcode-GTGCCAGCMGCCGCGG-3') and 907R (5'-CCGTCAATTCMTTTRAGTTT-3'), where the barcode was an eight-base sequence unique to each sample. The PCR process was conducted as follows: $95^{\circ} \mathrm{C}$ for $2 \mathrm{~min}$, followed by 25 cycles at $95^{\circ} \mathrm{C}$ for $30 \mathrm{~s}, 55^{\circ} \mathrm{C}$ for $30 \mathrm{~s}, 72^{\circ} \mathrm{C}$ for $30 \mathrm{~s}$ and a final extension at $72^{\circ} \mathrm{C}$ for $5 \mathrm{~min}$. PCR reactions were performed in triplicate. Each $20 \mu \mathrm{L}$ 
PCR reaction mixture contained $4 \mu \mathrm{L}$ of $5 \times$ FastPfu Buffer, $2 \mu \mathrm{L}$ of $2.5 \mathrm{mM}$ dNTPs, $0.8 \mu \mathrm{L}$ of each primer $(5 \mu \mathrm{M}), 0.4 \mu \mathrm{L}$ of FastPfu Polymerase, and $10 \mathrm{ng}$ of template DNA. Amplicons were extracted from 2\% agarose gels, purified using the AxyPrep DNA gel extraction kit (Axygen Biosciences, USA) and quantified using QuantiFluor ST (Promega, USA). Purified amplicons were pooled in equimolar and paired-end sequenced on an Illumina MiSeq platform. Finally, the raw reads were deposited into the National Center for Biotechnology Information Sequence Read Archive (SRA) database. Raw fastq files were demultiplexed and quality-filtered using Quantitative Insights into Microbial Ecology (QIIME). Operational Taxonomic Units (OTUs) were clustered with 97\% similarity cutoff using UPARSE (version 7.1 http://drive5.com/uparse/) and chimeric sequences were identified and removed using UCHIME. The phylogenetic affiliation of each 16S rRNA gene sequence was analyzed by RDP Classifier (http://rdp.cme.msu.edu/) against the silva (SSU115) 16S rRNA database using confidence threshold of $70 \%$.

\section{Results}

\subsection{Performance of FBMFCs continuously fed with cornstalk hydrolysate at different OLRs}

\subsubsection{Electrochemical performance}

As shown in Fig.1, electricity generation of two FBMFCs in parallel was both increased with the increasing OLRs of cornstalk hydrolysate from 0.82 to $8.16 \mathrm{~g} / \mathrm{L} / \mathrm{d}$. By comparison, FBMFC\#2 had a higher electricity production than FBMFC\#1. In addition, the two MFCs exhibited similar electricity fluctuations (decreased and then recovered) upon the increase of OLRs, probably due to the system disturbances from the feeding of cornstalk hydrolysate. Both FBMFCs achieved maximum voltage outputs of $378 \mathrm{mV}$ and $480 \mathrm{mV}$, respectively at $3.01 \mathrm{~g} / \mathrm{L} / \mathrm{d}$. No further increase was 
obtained at a higher OLR $(8.16 \mathrm{~g} / \mathrm{L} / \mathrm{d})$. These results demonstrated the feasibility of continuous power generation from cornstalk hydrolysate through FBMFC although the feedstock was of poor biodegradability with a BOD/COD of 0.16 .

Fig.2 further illustrates the electrochemical properties of FBMFC fed with cornstalk hydrolysate at different OLRs under open-circuit and closed-circuit conditions. Data of power density at $1.29 \mathrm{~g} / \mathrm{L} / \mathrm{d}$ were not presented due to the sudden failure of data acquisition system. FBMFC\#1 achieved a maximum power density $\left(596.23 \mathrm{~mW} / \mathrm{m}^{3}\right)$ and a highest open-circuit voltage $(0.53 \mathrm{~V})$ at $3.01 \mathrm{~g} / \mathrm{L} / \mathrm{d}($ Fig.2A, C), in comparison to $680 \mathrm{~mW} / \mathrm{m}^{3}$, and $0.5 \mathrm{~V}$ at $2.41 \mathrm{~g} / \mathrm{L} / \mathrm{d}$ for FBMFC\#2 (Fig.2B, D). These data were superior to those using similar MFC configuration fed with synthetic wastewater (He et al., 2015). This finding indicates that cornstalk hydrolysate may contain more diverse resources than synthetic wastewater although hydrolysate includes possible fermentation inhibitors, such as furan derivatives and phenols. Nyquist plots reveal the changes of $\mathrm{R}_{\text {in }}$ of MFC at different OLRs. As shown in Fig.2 E, F, $R_{\text {in }}$ of FBMFC\#1 was decreased from $45 \Omega$ at an OLR of $0.82 \mathrm{~g} / \mathrm{L} / \mathrm{d}$ to $40 \Omega$ at $8.16 \mathrm{~g} / \mathrm{L} / \mathrm{d}$. In comparison, FBMFC\#2 had a sharper decline of $\mathrm{R}_{\mathrm{in}}$ from $50 \Omega(0.82$ $\mathrm{g} / \mathrm{L} / \mathrm{d})$ to $28 \Omega(3.01 \mathrm{~g} / \mathrm{L} / \mathrm{d})$. This indicates that FBMFC\#2 might have a more efficient microbial electron transfer, supporting its higher power density than FBMFC\#1 (Fig.1).

Power density $\left(680 \mathrm{~mW} / \mathrm{m}^{3}\right)$ using cornstalk hydrolysate was higher than that $\left(590 \mathrm{~mW} / \mathrm{m}^{3}\right)$ using similar configuration fed with synthetic wastewater (He et al., 2015). While the COD removals (69.71-79.86\%) using cornstalk were lower than those (76.16\%-90.34\%) using synthetic wastewater at stable operations. There were several reasons: 1) Different from previous study (He et al., 2015), the CNTs used in this study was heat treated, which might strengthen the attachment of microbial consortia on CNTs and enhance power generation; 2) cornstalk hydrolysate is of poor biodegradability with a low BOD/COD value (0.16) (Fig.S1). Therefore, a lower COD removal was reached than using synthetic wastewater; 3) Cornstalk hydrolysate 
is a mixture of diverse organics. Such substrate may provide abundant carbon resources suitable for exoelectrogens (Pant et al., 2010), further leading to higher power production. The fluctuation of electricity, especially in FBMFC \#2 (Fig.1B) was due to the nature of the MFC configuration, where CNTs were simultaneously used as microbial carrier and anodic electrode (He et al., 2015). Electrons are transferred firstly between CNTs in FBMFC. The feedstock loading flow would impact the status of CNTs carriers, further leading to the fluctuation of electricity.

\subsubsection{Degradation efficiency of cornstalk hydrolysate}

As shown in Table 2, the two suits of FBMFCs in parallel achieved similar COD and TOC removals at different OLRs. Specifically, FBMFC\#2 obtained slightly higher removal efficiency (75.65-79.86\%) than FBMFC\#1 (72.55-76.01\%) at $\geq 3.01 \mathrm{~g} / \mathrm{L} / \mathrm{d}$, which further supported the higher power generation of the former. A highest COD removal (79.86\%) was achieved at $8.16 \mathrm{~g} / \mathrm{L} / \mathrm{d}$, whereas a maximum TOC removal $(84.67 \%)$ was obtained at $3.01 \mathrm{~g} / \mathrm{L} / \mathrm{d}$. The $\mathrm{pH}$ of the effluent was increased after MFC treatment, indicating that the removal of COD might be due to the combined effect of exoelectrogen and other competing processes, such as methanogenesis (Clauwaert and Verstraete, 2009). In addition, the concentrations of TVFAs in the influent were increased from $1.58 \mathrm{~g} / \mathrm{L}$ to $6.01 \mathrm{~g} / \mathrm{L}$ with the increasing OLRs. VFAs were dominated by acetic acid, succinic acid, and lactic acid. The concentration of TVFAs was remarkably decreased to $0.01 \sim 1.46 \mathrm{~g} / \mathrm{L}$ through $\mathrm{MFC}$. One interesting finding was that more lactic acid was retained at high OLRs $(8.16 \mathrm{~g} / \mathrm{L} / \mathrm{d})$, similar to previous results using synthetic wastewater as the feedstock for MFC (He et al., 2015).

This study demonstrates that a COD and TOC removal of about $80 \%$ was achieved at OLRs of up to $8.16 \mathrm{~g} / \mathrm{L} / \mathrm{d}$ while power (up to $680 \mathrm{~mW} / \mathrm{m}^{3}$ at $2.41 \mathrm{~g} / \mathrm{L} / \mathrm{d}$ ) was continuously produced in FBMFC fed with cornstalk hydrolysate. Previous study showed that it was possible to generate electricity from hydrolysate of cellulosic 
biomass, such as steam-exploded cornstalk (Zuo et al., 2006), wheat straw (Zhang et al., 2009) and rice straw (Wang et al., 2014). All these reports were performed in batch mode focused on either feasibility of electricity generation or the analysis of microbial diversity. The specific novelties and findings of this study were: 1) continuous production of power from cornstalk hydrolysate using a high-rate CNTs FBMFC reactor. From the perspective of practical application, continuous operation is of crucial important for biorefinery of biomass. What's more, the current study achieved the COD removals in a range of $69.71-79.86 \%$ at OLRs of 0.82 to 8.16 $\mathrm{g} / \mathrm{L} / \mathrm{d}$ (548-5475 mg COD/L), which were higher than those (49.4\%-72.0\%) using rice straw hydrolysate (100-400 mg COD/L) or those (60-70\%) using cornstalk hydrolysate (250-1000 mg COD/L). In addition, current study reveals the low BOD/COD (0.16) of cornstalk hydrolysate. In this regard, TOC instead of COD may be a better indicator of organic pollutants since recalcitrant organics, such as furan derivatives, phenols, ketones and soluble lignin, were involved in the hydrolysate (Fig.S1). The achieved TOC removal ranged from $68.81 \%$ to $84.67 \%$. Another aspect was that furan derivatives were completely degraded in both FBMFCs under all OLRs. As shown in Table 1, the concentrations of FUR and HMF in raw hydrolysate were $0.74 \mathrm{~g} / \mathrm{L}$ and $0.67 \mathrm{~g} / \mathrm{L}$. Considering the highest COD $(5475.2 \mathrm{mg} / \mathrm{L})$ used, at least 8 times dilution was needed, thus resulting in the real maximum concentrations of FUR and $\mathrm{HMF}$ at $0.09 \mathrm{~g} / \mathrm{L}$ and $0.08 \mathrm{~g} / \mathrm{L}$, respectively. One study suggested that threshold amounts for the negative influence of FUR and HMF on electricity generation from glucose were $4.8 \mathrm{mg} / \mathrm{L}$ and $0.63 \mathrm{~g} / \mathrm{L}$, respectively (Catal et al., 2008). In contrast, another study reported different findings and FUR up to $1.92 \mathrm{~g} / \mathrm{L}$ could be used as fuel for MFC (Luo et al., 2010). Based on the findings in this study and the literature, it is possible to remove and convert furan derivatives into electricity through microbial evolution in MFC environment. This is important since many fermentation processes (i.e. ethanol fermentation) suffer from the inhibition of furan derivatives in a biorefinery paradigm (Wang et al., 2013); 2) A new pretreatment method i.e. HTL 
was used for cornstalk. Previous investigations used steam-explosion (Zuo et al., 2006) or acids (Wang et al., 2014) to treat cornstalk or rice straw, respectively.

Distinguished from these studies, HTL was firstly used to treat cornstalk for MFC, although the hydrothermal method was employed for the pretreatment of wheat straw (Zhang et al., 2009). In comparison to other pretreatment approaches, HTL is promising as a gentle pretreatment of biomass due to its chemical-free fast process (0-60 min) (Nitsos et al., 2013).

\subsection{Characterization of microbial structure}

SEM shows the microbial morphology on the surface of CNTs in FBMFCs after 12 days' operation (Fig.S2). A diverse microbial community with bacteria of different sizes and shapes was formed. Specifically, two different microbial structures were observed. Most microorganisms irregularly aggregated in FBMFC\#1, while microorganisms in different sizes were distributed uniformly on the surface of CNTs in FBMFC\#2. Illumina MiSeq sequencing further characterized the microbial structure in FBMFCs. The richness of the samples was analyzed by OTUs through the rarefaction curve (Fig.3). The rarefaction curve was gentle in general, which ensured the rationality and accuracy of the results. As shown in Table 3, inoculum (373) and FBMFC\#1 (372) had the similar OTUs, higher than FBMFC\#2 (227). Ace and Chao indexes indicate the richness of the microbial communities, whereas Shannon and Simpson indexes represent the microbial diversity (Liu et al., 2015). Of the three samples (Table 3), the inoculum had the highest index of Shannon, whereas FBMFC\#1 had the highest indexes of Ace and Chao. Based on the analysis of biodiversity, there was no big difference of inoculum and FBMFC\#1. In comparison, a lowest Simpson index was achieved in FBMFC\#2, suggesting more specific strains were enriched in FBMFC\#2. 
To better characterize the phylogenetic differences between inoculum and FBMFCs, three different level classifications (i.e. Phylum, Family, and Genus), were presented in Fig.4. The significant difference of microbial diversity in inoculum, FBMFC\#1 and FBMFC\#2 was observed. At the phylum level, the contents of Spirochaetae and Proteobacteria in inoculum were $31.52 \%$ and $20.38 \%$, but they were not found in FBMFC. FBMFC\#1 and FBMFC\#2 resulted in different microbial structure. Specifically, FBMFC\#1 and FBMFC\#2 were respectively dominated by Bacteroidetes (46.54\%) and Chloroflexi (83.87\%), which were higher than those in the inoculum. In addition, the two FBMFCs had a 7-9\% of Actinobacteria, significantly higher than the inoculum (1.69\%). The Family level provides a more detailed analysis of microbial structure (Fig.4B). FBMFC\#1 was dominated by Streptococcaceae (34.52\%), and Pseudomonadaceae (17.41\%), in comparison to FBMFC\#2 by Rhizobiaceae (27.29\%), and Pseudomonadaceae (9.87\%). The Genus level analysis (Fig.4C) revealed that Lactococcus, Rhizobium and Pseudomonas were most dominant microbes in FBMFCs, in comparison to Longilinea and W5 norank in inoculum. In particular, FBMFC\#1 was dominated by Lactococcus $(33.57 \%)$, Pseudomonas (17.41\%), Syntrophobotulus (5.02\%), and Klebsiella (3.35\%), accounting for $59.35 \%$ of the total genus. FBMFC\#2 mainly consisted of Rhizobium (24.58\%), Pseudomonas (9.87\%), Klebsiella (7.60\%), Acinetobacter (6.10\%), Ochrobactrum (5.60\%), Achromobacter (5.31\%), Delftia (4.80\%), Flavobacterium (4.27\%) and Brevundimonas (4.11\%), accounting for $72.24 \%$ of the total genus.

Not surprisingly, both FBMFCs were dominated by diverse microbial communities because of complex compositions of cornstalk hydrolysate. Distinguished from previous study (Wang et al., 2014; Zhang et al., 2009), Proteobacteria which a number of exoelectrogens belong to, was not dominant on the electrode surface of FBMFC in this study. One possible reason is the different niches with diverse environment existing in MFC fed with lignocellulose hydrolysate (Wang et al., 2014), including degradation of macromolecules (i.e. cellulose and lignin) and 
conversion of small molecules (i.e. VFAs) into electricity. Considering the function of biochemical reactions, at least two types of microorganism will participate in electricity generation from cornstalk hydrolysate. Most reported important exoelectrogens, such as Geobacter sp. (Summers et al., 2010) and Shewanella sp. (Lovley, 2012), have the capability of converting simple and small molecules, such as acetic acid into electricity. In addition, a COD removal of about $80 \%$ from cornstalk hydrolysate with a very low BOD/COD, suggests that dominant bacteria might play an active role in the degradation of recalcitrant biomass existing in the hydrolysate. The different performance and microbial communities achieved by the two FBMFCs with the same configuration also reveal the complexity of feedstock. Over 4 and 9 genera were involved in FBMFC\#1 and FBMFC \#2, respectively with greater than 3\% abundance. Specifically, the most dominant genus in FBMFC\#1 was Lactococcus (33.57\%), whereas Rhizobium (24.58\%) in FBMFC\#2. Lactococcus is a genus of lactic acid bacteria. The high content of Lactococcus in FBMFC\#1 supports the metabolites analysis (Table 2), where more lactic acid $(0.90 \mathrm{~g} / \mathrm{L})$ was remained in FBMFC\#1 at high OLR (8.16 g/L/d). Regarding the dominant Rhizobium in FBMFC\#2, one MFC study using cellulose as the feedstock reported similar finding with over $30 \%$ population of Rhizobium (Ishii et al., 2008). Furthermore, Rhizobium was considered to be closely involved in cellulose degradation and possibly the electricity generation (Ishii et al., 2008).

\section{Conclusions}

The current study has shown the continuous production of electricity from cornstalk biomass after HTL treatment through CNT based FBMFC. About $80 \%$ of COD and TOC was effectively removed from cornstalk hydrolysate even with the low $\mathrm{BOD} / \mathrm{COD}(0.16)$, suggesting a promising approach to deal with recalcitrant organics. Illumina MiSeq sequencing reveals that the dominant bacteria in FBMFC were 
closely related to degradation of recalcitrant biomass, different from Proteobacteria, which a number of exoelectrogens belong to. Further study is needed to better understand the role of functional microbial community using cornstalk hydrolysate as the feedstock for MFC.

\section{Acknowledgement}

This work was financially supported by the Ministry of Water Resources Research Special Funds for Public Welfare Industry Project of China (201401078), Natural Science Foundation of China (21106080), NSFC-JST Cooperative Research Project (21161140328), and the Chinese Universities Scientific Fund (2012RC030).

\section{References}

[1] Ahmad, F., Atiyeh, M.N., Pereira, B., Stephanopoulos, G.N., 2013. A review of cellulosic microbial fuel cells: Performance and challenges. Biomass Bioenerg., 56, 179-188.

[2] Catal, T., Fan, Y., Li, K., Bermek, H., Liu, H., 2008. Effects of furan derivatives and phenolic compounds on electricity generation in microbial fuel cells. J. Power Sources, 180, 162-166.

[3] Clauwaert, P., Verstraete, W., 2009. Methanogenesis in membraneless microbial electrolysis cells. Appl. Microbiol. Biotechnol., 82, 829-836.

[4] Elkins, J.G., Raman, B., Keller, M., 2010. Engineered microbial systems for enhanced conversion of lignocellulosic biomass. Curr. Opin. Biotechnol., 21, 657-662.

[5] Gregoire, K.P., Becker, J.G., 2012. Design and characterization of a microbial fuel cell for the conversion of a lignocellulosic crop residue to electricity. Bioresour. Technol., 119, 208-215.

[6] Hassan, S.H.A., Gad El-Rab, S.M.F., Rahimnejad, M., Ghasemi, M., Joo, J.-H., Sik-Ok, Y., Kim, I.S., Oh, S.-E., 2014. Electricity generation from rice straw using a microbial fuel cell. Int. J. Hydrogen Energy, 39, 9490-9496.

[7] He, Y., Liu, Z., Xing, X.-h., Li, B., Zhang, Y., Shen, R., Zhu, Z., Duan, N., 2015. Carbon nanotubes simultaneously as the anode and microbial carrier for up-flow fixed-bed microbial fuel cell. Biochem. Eng. J., 94, 39-44.

[8] Himmel, M. 2008. Biomass Recalcitrance: Deconstructing the Plant Cell Wall for Bioenerg. Wiley-Blackwell. 
[9] Ishii, S.i., Shimoyama, T., Hotta, Y., Watanabe, K., 2008. Characterization of a filamentous biofilm community established in a cellulose-fed microbial fuel cell. BMC Microbiol., 8, 6 .

[10] Kumaraswamy, R., Amha, Y.M., Anwar, M.Z., Henschel, A., Rodríguez, J., Ahmad, F., 2014. Molecular analysis for screening human bacterial pathogens in municipal wastewater treatment and reuse. Environ. Sci. Technol., 48, 11610-11619.

[11] Li, H., Chen, H., 2008. Detoxification of steam-exploded corn straw produced by an industrial-scale reactor. Process Biochem., 43, 1447-1451.

[12] Li, H., Liu, Z., Zhang, Y., Li, B., Lu, H., Duan, N., Liu, M., Zhu, Z., Si, B., 2014. Conversion efficiency and oil quality of low-lipid high-protein and high-lipid low-protein microalgae via hydrothermal liquefaction. Bioresour. Technol., 154, 322-329.

[13] Liu, Z., Zhang, C., Wang, L., He, J., Li, B., Zhang, Y., Xing, X.-H., 2015. Effects of furan derivatives on biohydrogen fermentation from wet steam-exploded cornstalk and its microbial community. Bioresour. Technol., 175, 152-159.

[14] Logan, B.E., Rabaey, K., 2012. Conversion of wastes into bioelectricity and chemicals by using microbial electrochemical technologies. Science, 337, 686-690.

[15] Lovley, D.R., 2012. Electromicrobiology. Annu. Rev. Microbiol., 66, 391-409.

[16] Luo, Y., Liu, G., Zhang, R., Zhang, C., 2010. Power generation from furfural using the microbial fuel cell. J. Power Sources, 195, 190-194.

[17] Lynd, L., Zyl, W., McBride, J., Laser, M., 2005. Consolidated bioprocessing of cellulosic biomass: an update. Curr. Opin. Biotechnol., 16, 577-583.

[18] Möller , M., Nilges , P., Harnisch, F., Schröder, U., 2011. Subcritical Water as Reaction Environment: Fundamentals of Hydrothermal Biomass Transformation. ChemSusChem, 4, 566-579.

[19] Nitsos, C.K., Matis, K.A., Triantafyllidis, K.S., 2013. Optimization of hydrothermal pretreatment of lignocellulosic biomass in the bioethanol production process. ChemSusChem, 6, 110-122.

[20] Oliveira, V.B., Simões, M., Melo, L.F., Pinto, A.M.F.R., 2013. Overview on the developments of microbial fuel cells. Biochem. Eng. J., 73, 53-64.

[21] Pant, D., Van Bogaert, G., Diels, L., Vanbroekhoven, K., 2010. A review of the substrates used in microbial fuel cells (MFCs) for sustainable energy production. Bioresour. Technol., 101, 1533-1543.

[22] Ren, Z., Ward, T., Regan, J., 2007. Electricity production from cellulose in a microbial fuel cell using a defined binary culture. Environ. Sci. Technol., 41, 4781-4786.

[23] Rezaei, F., Richard, T.L., Logan, B.E., 2008. Enzymatic hydrolysis of cellulose coupled with electricity generation in a microbial fuel cell. Biotechnol. Bioeng., 101, 1163-1169.

[24] Rismani-Yazdi, H., Christy, A.D., Dehority, B.A., Morrison, M., Yu, Z., Tuovinen, O.H., 2007. Electricity generation from cellulose by rumen microorganisms in microbial fuel cells. Biotechnol. Bioeng., 97, 1398-1407.

[25] Summers, Z.M., Fogarty, H.E., Leang, C., Franks, A.E., Malvankar, N.S., Lovley, D.R., 2010. Direct exchange of electrons within aggregates of an evolved syntrophic coculture of anaerobic bacteria. Science, 330, 1413-1415. 
[26] Tian, C., Li, B., Liu, Z., Zhang, Y., Lu, H., 2014. Hydrothermal liquefaction for algal biorefinery: A critical review. Renew. Sus. Energy Rev., 38, 933-950.

[27] Wang, X., Feng, Y., Wang, H., Qu, Y., Yu, Y., Ren, N., Li, N., Wang, E., Lee, H., Logan, B.E., 2009. Bioaugmentation for electricity generation from corn stover biomass using microbial fuel cells. Environ. Sci. Technol., 43, 6088-6093.

[28] Wang, X., Tang, J., Cui, J., Liu, Q., Giesy, J.P., Hecker, M., 2014. Synergy of electricity generation and waste disposal in solid-state microbial fuel cell (MFC) of cow manure composting. Int. J. Electrochem. Sci.,, 9, 3144 - 3157.

[29] Wang, X., Yomano, L.P., Lee, J.Y., York, S.W., Zheng, H., Mullinnix, M.T., Shanmugam, K.T., Ingram, L.O., 2013. Engineering furfural tolerance in Escherichia coli improves the fermentation of lignocellulosic sugars into renewable chemicals. PNAS, 110 , 4021-4026.

[30] Wang, Z., Lee, T., Lim, B., Choi, C., Park, J., 2014. Microbial community structures differentiated in a single-chamber air-cathode microbial fuel cell fueled with rice straw hydrolysate. Biotechnol.Biofuels, 7.

[31] Zhang, Y., Min, B., Huang, L., Angelidaki, I., 2009. Generation of electricity and analysis of microbial communities in wheat straw biomass-powered microbial fuel cells. Appl. Environ. Microbiol., 75, 3389-3395.

[32] Zuo, Y., Maness, P.C., Logan, B., 2006. Electricity production from steam-exploded corn stover biomass. Energy Fuels, 20, 1716-1721. 


\section{Figure captions}

Fig.1 Electricity generation (B) of CNT FBMFCs at different OLRs (A).

Fig.2 Electrochemical properties of FBMFC\#1 (A, C, E) and FBMFC\#2 (B, D, F) at different OLRs (g COD/L/d). Power curves (A, B); Polarization curves (C, D); Nyquist plots (E, F).

Fig.3 Rarefaction curve of microbial communities in inoculum and FBMFCs at a 97\% similarity level

Fig.4 Taxonomic classification microbial communities of inoculum and FBMFCs at the phyla (A), families (B), and genera (C) levels through Illumina Miseq sequencing. Phyla, Families, and Genera in less than $1 \%$ of total composition in all three libraries were classified as "others". 
Table 1 Characterization of cornstalk before and after HTL.

\begin{tabular}{lcc}
\hline Components & Cornstalk before HTL & Cornstalk after HTL \\
\hline Solid contents $(\%)$ & & \\
Cellulose & $45.06 \pm 0.70$ & N.D. \\
Hemicellulose & $29.68 \pm 0.31$ & N.D. \\
Lignin & $5.65 \pm 0.27$ & $22.08 \pm 2.74$ \\
Ash content & $3.98 \pm 0.05$ & $4.06 \pm 0.24$ \\
Others & $10.26 \pm 0.34$ & $73.86 \pm 2.51$ \\
Liquid information & & \\
pH & - & 46.60 \\
Reducing sugars $(\mathrm{g} / \mathrm{L})$ & - & 4.99 \\
HMF $(\mathrm{g} / \mathrm{L})$ & - & 0.79 \\
FUR $(\mathrm{g} / \mathrm{L})$ & - & 0.74 \\
COD $(\mathrm{g} / \mathrm{L})$ & - & $44.94 \pm 0.18$ \\
BOD $(\mathrm{g} / \mathrm{L})$ & - & $7.37 \pm 0.09$ \\
BOD/COD & - & 0.16 \\
TOC $(\mathrm{g} / \mathrm{L})$ & - & 18.51 \\
IC $(\mathrm{g} / \mathrm{L})$ & - & 0.06 \\
TVFAs $(\mathrm{g} / \mathrm{L})$ & - & 64.59 \\
Formic acid $(\mathrm{g} / \mathrm{L})$ & - & 21.86 \\
Lactic acid $(\mathrm{g} / \mathrm{L})$ & - & 13.62 \\
Acetic acid $(\mathrm{g} / \mathrm{L})$ & - & 11.20 \\
Succinic acid $(\mathrm{g} / \mathrm{L})$ & - & 10.40 \\
Propionic acid $(\mathrm{g} / \mathrm{L})$ & - & 2.45 \\
Butyric acid $(\mathrm{g} / \mathrm{L})$ & - & 5.06 \\
\hline N.D & &
\end{tabular}

N.D., not detected. 
Table 2 Analysis of influent and effluent of anode chamber of FBMFC

\begin{tabular}{|c|c|c|c|c|c|c|c|c|c|c|c|c|c|}
\hline \multirow{2}{*}{$\begin{array}{c}\text { OLR } \\
(\mathrm{g} / \mathrm{L} / \mathrm{d})\end{array}$} & \multirow{2}{*}{ Samples } & \multirow{2}{*}{$\begin{array}{c}\text { COD } \\
(\mathrm{mg} / \mathrm{L})\end{array}$} & \multirow{2}{*}{$\begin{array}{c}\text { COD } \\
\text { removal } \\
(\%)\end{array}$} & \multirow{2}{*}{$\begin{array}{c}\text { TOC } \\
(\mathrm{mg} / \mathrm{L})\end{array}$} & \multirow{2}{*}{$\begin{array}{c}\text { TOC } \\
\text { removal } \\
(\%)\end{array}$} & \multirow{2}{*}{$\mathbf{p H}$} & \multicolumn{7}{|c|}{ VFAs $(g / L)$} \\
\hline & & & & & & & $\begin{array}{c}\text { Formic } \\
\text { acid }\end{array}$ & $\begin{array}{l}\text { Lactic } \\
\text { acid }\end{array}$ & $\begin{array}{l}\text { Acetic } \\
\text { acid }\end{array}$ & $\begin{array}{c}\text { Succinic } \\
\text { acid }\end{array}$ & $\begin{array}{c}\text { Propionic } \\
\text { acid }\end{array}$ & $\begin{array}{c}\text { Butyric } \\
\text { acid }\end{array}$ & TVFAs \\
\hline \multirow{4}{*}{0.82} & In. & $548.25 \pm 7.49$ & - & 208.00 & - & 7.00 & 0 & 0.03 & 0.54 & 0.96 & 0 & 0.04 & 1.58 \\
\hline & Eff. \#1 & 135.23 & 75.33 & 52.96 & 74.54 & 7.16 & 0 & 0.01 & 0 & 0.07 & 0 & 0 & 0.08 \\
\hline & Eff.\#2 & $150.51 \pm 5.03$ & 72.55 & 48.08 & 76.88 & 7.29 & 0 & 0.01 & 0 & 0 & 0 & 0 & 0.01 \\
\hline & In. & $863.25 \pm 24.35$ & - & 290.03 & - & 7.00 & 0 & 0.11 & 0.67 & 1.19 & 0 & 0.23 & 2.21 \\
\hline \multirow[t]{3}{*}{1.29} & Eff.\#1 & $216.95 \pm 1.51$ & 74.87 & 76.32 & 73.69 & 7.01 & 0 & 0 & 0.02 & 0.06 & 0 & 0 & 0.08 \\
\hline & Eff.\#2 & $261.51 \pm 7.93$ & 69.71 & 76.32 & 73.69 & 7.03 & 0 & 0 & 0 & 0.01 & 0 & 0 & 0.01 \\
\hline & In. & $1616.5 \pm 48.32$ & - & 523.12 & - & 7.00 & 0.09 & 0.67 & 0.68 & 1.99 & 0.38 & 0.04 & 3.84 \\
\hline \multirow[t]{3}{*}{2.41} & Eff.\#1 & $411.67 \pm 6.45$ & 74.53 & 144.48 & 72.38 & 7.24 & 0 & 0 & 0.15 & 0.13 & 0 & 0 & 0.28 \\
\hline & Eff.\#2 & $458.63 \pm 9.35$ & 71.63 & 163.14 & 68.81 & 7.26 & 0 & 0.04 & 0.09 & 0.14 & 0.02 & 0 & 0.29 \\
\hline & In. & $2023.55 \pm 53.55$ & - & 979.4 & - & 7.00 & 0.13 & 0.55 & 1.14 & 2.04 & 0.04 & 0.19 & 4.09 \\
\hline \multirow[t]{3}{*}{3.01} & Eff.\#1 & $555.38 \pm 33.28$ & 72.55 & 172.05 & 82.43 & 7.86 & 0 & 0.03 & 0.27 & 0.25 & 0 & 0 & 0.55 \\
\hline & Eff.\#2 & $492.68 \pm 15.52$ & 75.65 & 150.10 & 84.67 & 7.70 & 0 & 0.15 & 0.14 & 0.13 & 0.03 & 0 & 0.45 \\
\hline & In. & $5475.2 \pm 57.9$ & - & 2098.5 & - & 7.00 & 0.01 & 1.92 & 1.56 & 2.03 & 0.08 & 0.40 & 6.01 \\
\hline \multirow[t]{2}{*}{8.16} & Eff.\#1 & $1313.38 \pm 4.26$ & 76.01 & 509.50 & 75.73 & 7.60 & 0 & 0.90 & 0.25 & 0.23 & 0.08 & 0 & 1.46 \\
\hline & Eff.\#2 & $1102.65 \pm 30.40$ & 79.86 & 503.50 & 76.00 & 7.72 & 0 & 0.68 & 0.11 & 0.07 & 0.06 & 0 & 0.93 \\
\hline
\end{tabular}

In., Eff.\#1, Eff.\#2 were Influent, and Effluent from FBMFC\#1 and FBMFC\#2, respectively. 
Table 3 Biodiversity analysis of the microbial community among Inoculum, FBMFC\#1, and FBMFC\#2.

\begin{tabular}{ccccccc}
\hline \multirow{2}{*}{ Samples } & \multirow{2}{*}{ Reads } & \multicolumn{5}{c}{ Similarity Level $=\mathbf{0 . 9 7}$} \\
\cline { 3 - 7 } & & OTUs $^{\mathbf{a}}$ & Ace & Chao & Shannon & Simpson \\
\hline Inoculum & 34107 & 373 & 401 & 416 & 3.57 & 0.0829 \\
FBMFC\#1 & 38918 & 372 & 426 & 443 & 3.33 & 0.1143 \\
FBMFC\#2 & 39278 & 227 & 246 & 246 & 3.33 & 0.0614 \\
\hline
\end{tabular}

${ }^{\text {a }}$ OTUs: operational taxonomic units. 
Fig.1 Electricity generation (B) of CNT FBMFCs at different OLRs (A).
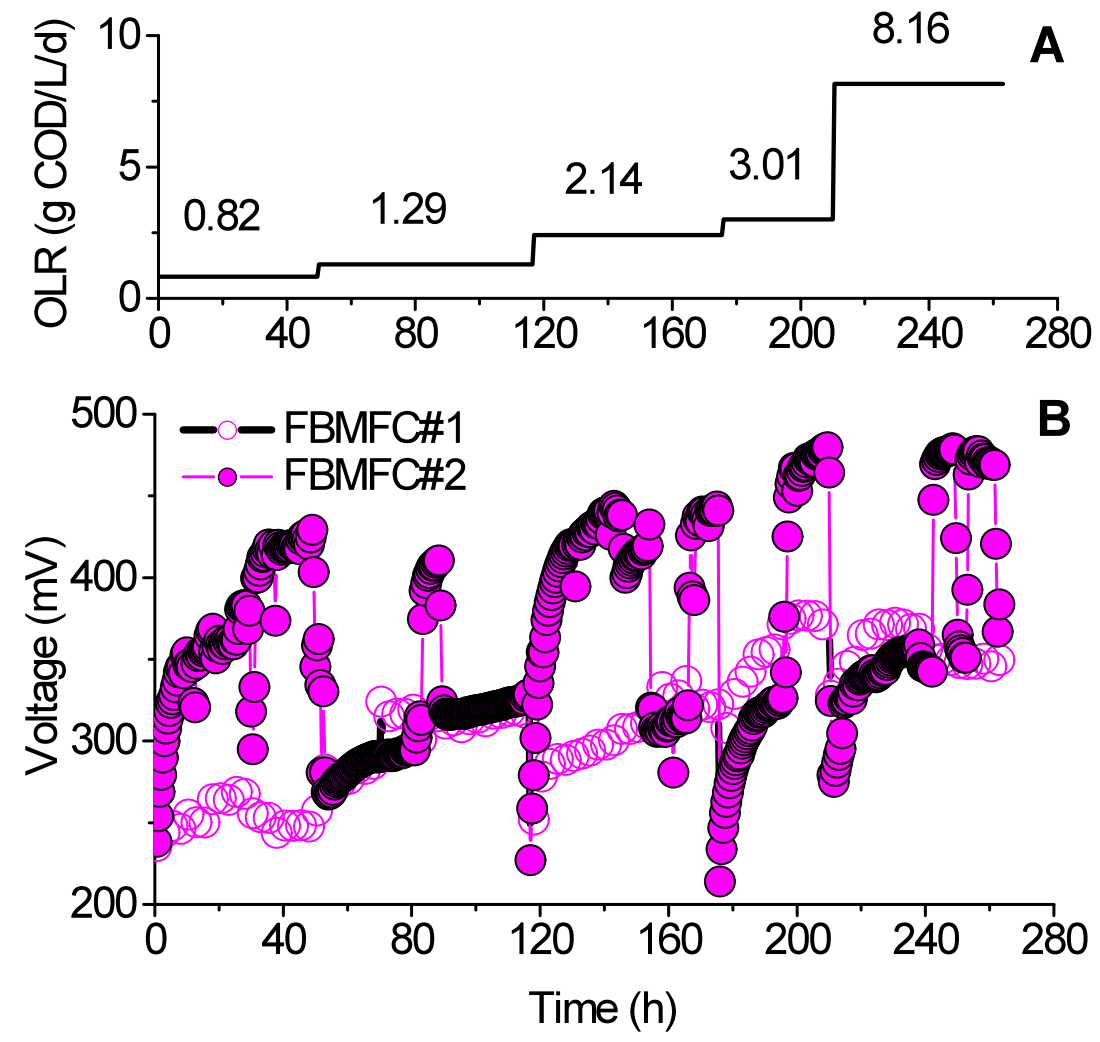
Fig.2 Electrochemical properties of FBMFC\#1 (A, C, E) and FBMFC\#2 (B, D, F) at different OLRs (g COD/L/d). Power curves (A, B); Polarization curves $(\mathrm{C}, \mathrm{D})$; Nyquist plots (E, F).
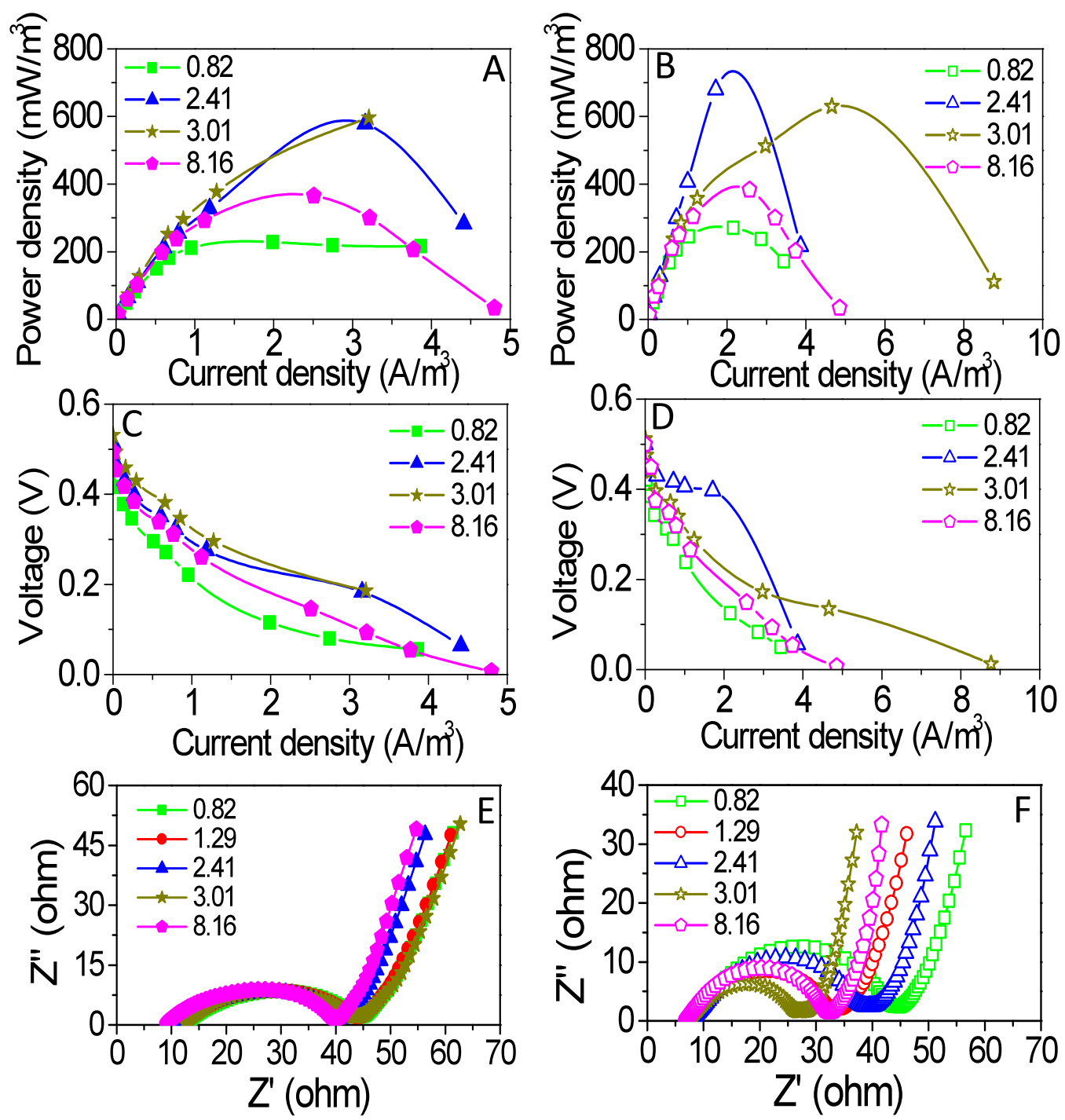
Fig.3 Rarefaction curve of microbial communities in inoculum and FBMFCs at a $97 \%$ similarity level.

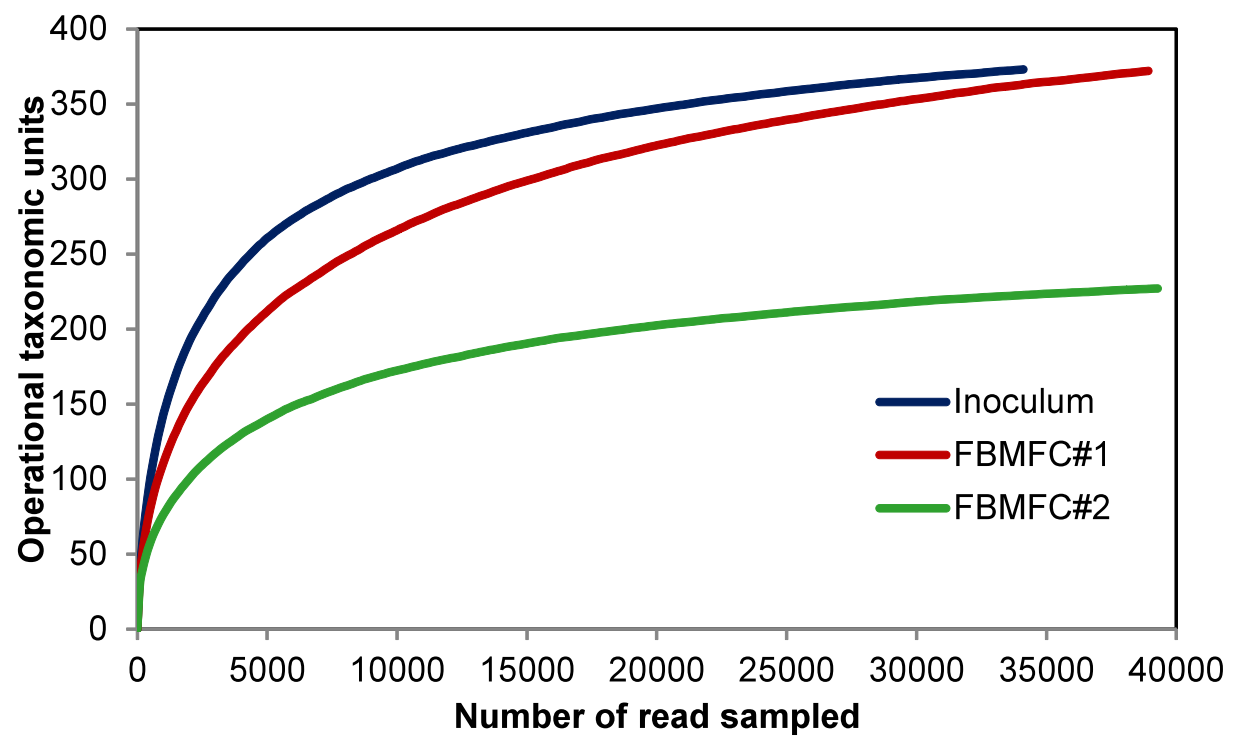


Fig.4 Taxonomic classification microbial communities of inoculum and FBMFCs at the phyla (A), families (B), and genera (C) levels through Illumina Miseq sequencing. Phyla, Families, and Genera in less than $1 \%$ of total composition in all three libraries were classified as "others".
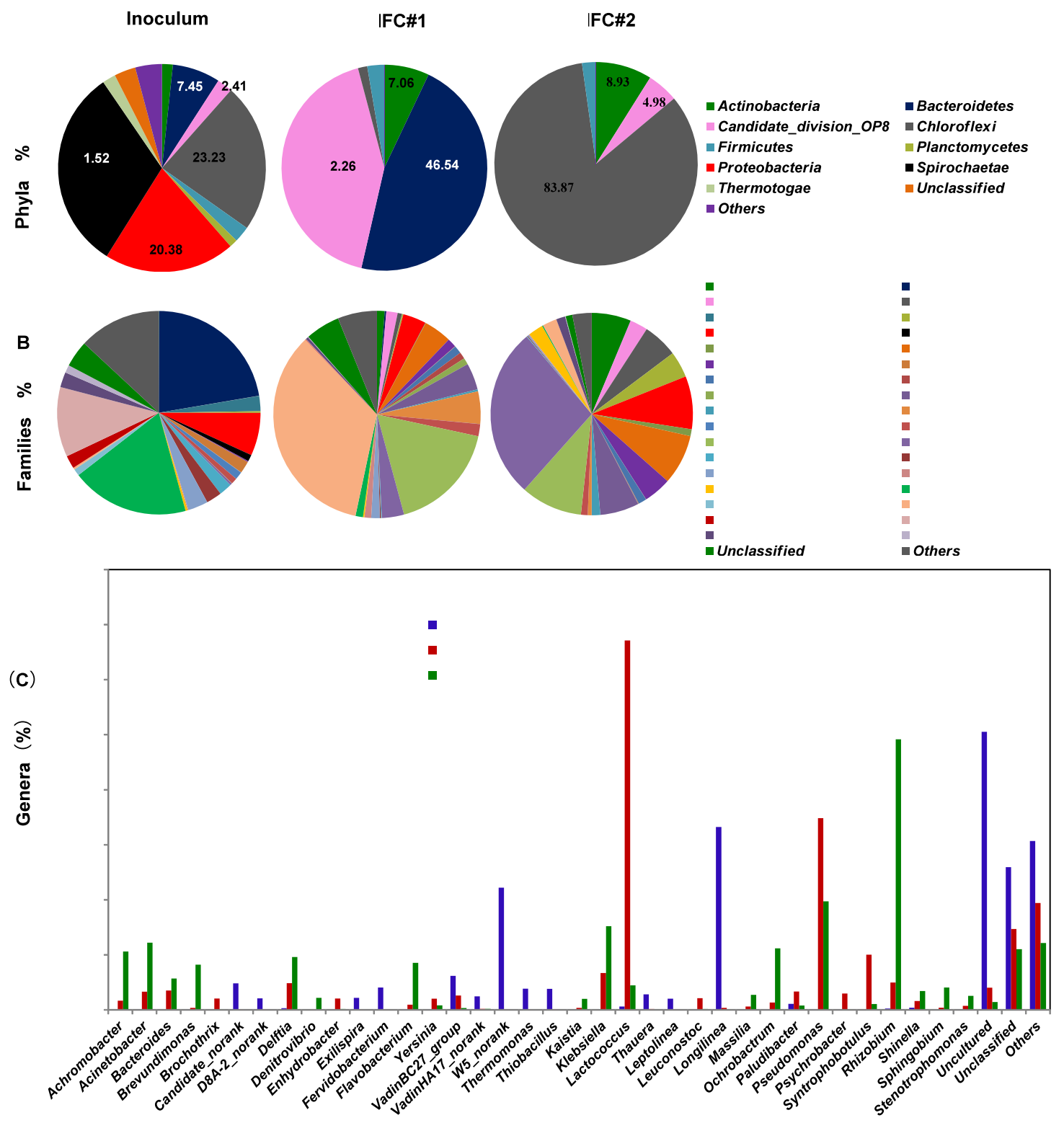